\title{
L'ETRE EN FORME. DIALECTIQUE ET PHENOMENOLOGIE DANS LA derniere philosophie de Merleau-Ponty, Fano, Mimesis, 2016, 310 PP. DE MARIANA LARISON
}

\author{
Esteban García \\ Universidad de Buenos Aires \\ Consejo Nacional de Investigaciones Científicas y Técnicas \\ baneste72@gmail.com
}

Los últimos desarrollos filosóficos de M. Merleau-Ponty, plasmados en cursos y escritos de carácter no pocas veces elusivo y fragmentario, manifiestan una diversidad de intereses aparentemente tan dispares como el estructuralismo lingüístico, el psicoanálisis, la literatura y la pintura contemporáneas, la historia filosófica de la noción de naturaleza o los desarrollos empíricos de la embriología y la etología. No sorprende entonces que en las últimas décadas haya crecido el interés académico en explorar aspectos específicos de este cuantioso y multifacético capital conceptual. Sin embargo, la obra de Mariana Larison -Doctora en Filosofía por la Universidad París I-Sorbonne y con una continuada labor docente e investigativa en las Universidades de São Paulo y Buenos Aires- realiza una tarea ambiciosa y singular en el contexto de los estudios merleau-pontianos: no solamente da cuenta de cada una de estas vertientes en las que se ramifica la última producción del filósofo, sino que logra develar los ne- 
xos que llevan de unas a otras integrándolas en un mismo proyecto filosófico. Otorgando especial atención a seminarios publicados e inéditos, la autora recorre el camino que lleva a Merleau-Ponty desde la poco explorada indagación del filósofo acerca de la dialéctica de mediados de los '50, hasta los últimos escritos en que aquella indagación seminal cristaliza en la formulación de una ontología de las formas sensibles que es a la vez una fenomenología -inscripta con pleno derecho en la línea de la investigación abierta por E. Husserl-.

El primer capítulo - "Le tournant de l'expérience"- se enfoca en el período que va desde principios de los años '50 hasta el seminario acerca de la dialéctica de los años 1955-56, años a los que corresponden los primeros cursos dictados por Merleau-Ponty en el Collège de France acerca de tópicos tales como la expresión, el lenguaje, la historia y la institución. La indagación de estas temáticas, que desde la década anterior el filósofo se había propuesto investigar como continuaciones o complementos necesarios de una fenomenología del cuerpo y la percepción expuesta en su obra más célebre, van a conducirlo a una radicalización y revisión de los conceptos básicos de su filosofía que, pasando por la historia, la dialéctica y la naturaleza, culminarán en el esbozo de una original ontología. Estos son asimismo los años de su alejamiento simultáneo del PCF y de su amigo Sartre, rupturas cuyo significado filosófico la autora precisa como el de un giro, "no hacia otra cosa que la historia, sino hacia otra manera de pensar la historia" (p. 36) más allá del supuesto de una lógica objetiva del acontecer hacia la concepción de un principio de inteligibilidad urdido en el seno mismo de los acontecimientos. Se trata a la vez y finalmente del período en el cual se gestan Les aventures de la dialectique (1955), donde la propuesta inicial de "revisar el hegelianismo" toma la forma de una crítica de la historia del marxismo. A través del análisis de conceptos antinómicos de Weber, Lukács, Lenin, Trotski o Sartre se trasluce la dificultad de pensar el problema de la mediación desde la interpretación marxista de la historia. Ciertamente, esto no lleva a Merleau-Ponty a recusar la dialéctica sino a purgarla de dogmatismo y redescubrirla más allá del hegelianismo y el marxismo tradicional, como "característica de la filosofía y no de una filosofía" (p. 43). Para comprender el problema de la historia, sintetiza así M. Larison, "sería necesario abandonar la dialéctica de la historia y dirigirse hacia la historia de la dialéctica" (p. 42). De este modo, los cursos de 1955-56 acerca de la dialéctica se revelan decisivos en el giro que definirá la última filosofía merleau-pontiana, y los problemas allí abor- 
dados son retomados en el último curso dictado por el filósofo en 1960-61 ("Philosophie et non-philosophie depuis Hegel"). Indagando en estos dos cursos y un número de artículos y notas de trabajo redactados en el período que se extiende entre ambos, M. Larison acompaña la búsqueda merleau-pontiana de una "buena dialéctica" - aquella que será luego designada por el filósofo como "hiperdialéctica" - definida preliminarmente como aquella en que las diferencias no son nunca subsumidas por la síntesis o la identidad, ni tampoco se plasman en "una escisión ontológica radical entre el orden de Para-sí y el del En-sí" (p. 47). El cumplimiento de ambas exigencias posiciona a Merleau-Ponty en un lugar singular dentro del debate que enfrentara a fines de los años '50 las interpretaciones de la dialéctica propuestas por A. Kojève y Tran-Duc-Thao. Si Merleau-Ponty comparte con el segundo y a diferencia del primero la necesidad de reconocer una dialéctica de la naturaleza y un elemento de negatividad inherente desde siempre al Ser, intenta sin embargo pensar originalmente "el movimiento sin síntesis del Ser" (p. 53), en cuya dialéctica toda identidad se revela provisoria y abierta a nuevas negaciones.

Es así que partiendo de la urgencia epocal de repensar la historia MerleauPonty se ve llevado a redescubrir la dialéctica, empresa para la que a la vez se revela indispensable reflexionar sobre la noción de naturaleza, tema de los cursos dictados por el filósofo durante 1956-57 y en los que se detiene minuciosamente el segundo capítulo de esta obra: "L'ontologie voilée de la nature". En estos cursos Merleau-Ponty identifica el "giro de los cartesianos" en torno a la noción de naturaleza con la radicalización de la idea de infinito heredada de la tradición judeo-cristiana, movimiento que redunda en el concepto de una naturaleza exterior a Dios y al hombre y en una concepción objetiva del Ser. Tanto Descartes como Leibniz habrían enunciado así - con los vocabularios de la esencia y el hecho, lo posible y lo actual- la misma idea del infinito positivo, derivando la naturaleza de la Idea y de la perfección y estableciendo un ser excluyente del no-ser. Sin embargo, desde Descartes se reconoció simultáneamente que el ser de los organismos vivientes y del cuerpo se resistía a esta concepción objetiva y demandaba pensar la producción natural como infinito negativo. Si Kant formuló agudamente el problema en su tercera crítica, fue en cambio Schelling quien marcó, en la visión merleau-pontiana, un giro en la concepción moderna de la naturaleza, al pensar el infinito como Abismo y la naturaleza como "naturaleza primordial" y "principio bárbaro": una naturaleza vivida 
en la experiencia perceptiva en estado de indivisión y a la que la reflexión filosófica retorna como hacia lo irreflejo. Con Schelling, constata la autora, Merleau-Ponty comienza el análisis de una nueva línea de pensamiento acerca de la naturaleza en la que el mismo filósofo se inscribirá, y que hará escala en Bergson, Whitehead y Husserl. En Bergson, por su parte, encuentra Merleau-Ponty formulada una clara crítica a la idea de nada como pura nada en términos de pseudo-problema o flatus vocis, y el consiguiente esbozo de la concepción de un ser como plenitud que dura y en el que se reconoce, no la ejecución de una producción infinita, sino una productividad natural que incorpora la negatividad. Esta propuesta bergsoniana es sin embargo traicionada por la persistencia de un cierto positivismo ontológico, y será sólo en el pensamiento de Husserl examinado a continuación en los cursos del filósofo- que Merleau-Ponty encuentra efectivamente el vocabulario en el que entronca su propia reflexión. Ya desde el Prefacio a su Phénoménologie de la perception Merleau-Ponty había identificado - tal como lo hace en estos nuevos cursos - tendencias en conflicto en el pensamiento de Husserl, que hacían de la actitud natural, por un lado, un estado de ignorancia a superar, y por otro una dimensión rica de sentido a ser explicitada. La Naturaleza, concomitantemente, es o bien reducida a su dimensión noemática, o pensada "como dimensión anterior a todo trabajo teórico y como su condición de posibilidad" (p. 97). Sin embargo, M. Larison identifica la singularidad de esta relectura merleau-pontiana de Husserl respecto de la correspondiente a la década previa en que "no se limita a la sola evaluación de tendencias opuestas, sino que revela una tercera vía del pensar husserliano, menos explícita que sugerida, hacia una nueva ontología" (p. 107), cuyas figuras son el entrelazamiento, el Ineinander, la mediación. La autora complementa en este punto el análisis de los cursos sobre la naturaleza en Husserl (1956-57) con otros posteriores (1959-60: "Husserl aux limites de la phénoménologie"), para discernir prolijamente las diversas operaciones merleau-pontianas de lectura frente a los textos del maestro alemán. Por un lado, Merleau-Ponty persigue en Husserl "una concepción de la idealidad que permite pensar el sentido como unidad indisociable de trascendencia y encarnación, unidad de un ser-ahí y de un ser-a-distancia". Por otro lado, esta concepción de la idealidad habilita un pensamiento original de la "infinitud de la apertura del mundo como horizonte de todos los horizontes" o como horizonte de sentido en general (p. 110). La primera búsqueda, como advierte perspicazmente la autora, debe atravesar 
el difícil escollo de la teleología histórica husserliana según la cual el horizonte, aun si infinito, no deja de ser una identidad a ser desplegada, mientras que Merleau-Ponty lo concibe como inagotable de derecho y sin un sentido predado. La segunda línea de análisis lleva a Merleau-Ponty a encontrar en la noción husserliana de la Tierra como "horizonte de todos los horizontes, apertura general al ser y a los otros, suelo de toda experiencia" (p. 119) la culminación de sus previos análisis histórico-filosóficos de la noción de Naturaleza. En la síntesis de la autora, "en el seno de las diversas dimensiones husserlianas del Welt -histórica, como entorno o, más originariamente, suelo- Merleau-Ponty halla finalmente una oposición determinante: la que apunta a la red conceptual de la Idea en tanto que infinitud positiva, a la cual se opondría la infinitud abierta e inacabada del mundo" (p. 119). El derrotero del análisis histórico-filosófico merleau-pontiano de la noción de naturaleza, a la luz de estos análisis, apunta no meramente a la elucidación de una dimensión regional sino "a la cuestión metafísica de la Naturaleza como preámbulo a una nueva ontología" (p. 121). Sin embargo, esta nueva ontología recibe hasta este punto una caracterización predominantemente negativa, por contraste con la "ontología del objeto, caracterizada por una concepción del ser como en-sí, del infinito como actualidad positiva, de lo real como actualidad y de la nada como nichtiges Nichts" ( $p$. 122). Sólo se esboza para Merleau-Ponty con el análisis de los últimos autores un nuevo modo de pensar la dialéctica y la ontología caracterizado por la vía de la mediación, y nos conduce hacia el campo de lo percibido como dimensión privilegiada de esta mediación.

El tercer capítulo de la obra - "La construction de la nouvelle ontologie"se divide en tres secciones, dedicándose la primera de ellas a la cuestión de la corporalidad de los seres vivos, tema que se vinculará en Merleau-Ponty a la idea de una vida intencional, y por esta vía, a la de una ontología de lo percibido. El recurso del filósofo a las ciencias biológicas le permite acercarse a una interrogación más profunda acerca de los seres vivos y de la vida misma como totalidades dinámicas en las que el sentido y lo sensible son inseparables, interrogación que los análisis de Larison ponen acertadamente en relación con las previas reflexiones de Merleau-Ponty acerca de la percepción del movimiento en su curso acerca de Le Monde sensible et le monde de l'expression (195253). El proceso vital hace necesario contar con un "no-ser operante", una "falta que impulsa" o una negatividad eficaz que no es nada, sin dotar a esta falta de 
un contenido positivo ni reificarla como en las concepciones tradicionales de la vida. Así, en suma, "la vida puede ser definida como la estructuración de la auto-diferenciación, ya que su movimiento no es jamás finalizado, y que a la vida del viviente le resta siempre ser completada" (p. 139). La segunda sección se vuelve hacia la especificidad del cuerpo humano tal como es abordada en los cursos de 1959-60, donde tópicos característicos de los desarrollos previos del filósofo tales como el esquema corporal o el sentir se integran en el marco más amplio de una ontología de lo sensible. En este seminario, las dos cuestiones recién mentadas derivan y se articulan en una tercera que $M$. Larison explorará en profundidad: la de lo simbólico, anudada en una misma red conceptual con la de lo imaginario. La autora caracteriza tres fases - "fenomenológica", "psicológica" y "ontológica" - en la reflexión merleau-pontiana que va desde lo imaginario hacia lo simbólico. En contraste con la reflexión sartriana que escindía esencialmente la percepción de la imaginación, mediante el concepto de "esquema corporal" - deudor de la "imagen del cuerpo" de P. Schilder- la Phénoménologie de la perception realiza una "incorporación de la dimensión imaginaria en la conformación misma del cuerpo vivido, es decir, en el sujeto de la percepción en tanto tal" (p. 150). En sus posteriores cursos de psicología infantil Merleau-Ponty recurre a elementos psicoanalíticos para indagar en el rol clave que juega lo imaginario en la formación de sí mismo y los objetos, elementos que sin embargo no articulará en una reflexión original hasta una tercera fase que comienza a mediados de los años '50. En la visión de la autora, en esta última fase "ontológica" Merleau-Ponty escapa "de la dicotomía sartriana entre lo imaginario y lo real por vía de la introducción de un tercer orden [lo simbólico] que revelará la naturaleza de los dos primeros" (p. 159). El sujeto de la estructuración pre-objetiva del mundo es ahora el inconciente, considerado por Merleau-Ponty en su doble dimensión de "inconciente primordial" idéntico al sentir, y de matriz simbólica "incorporada en el mismo momento que todas las relaciones diferenciales al interior de las cuales se instituye el sí mismo" ( $p$. 165). En una tercera y última sección del capítulo, la obra aborda la articulación entre el ser del cuerpo, objeto privilegiado de elucidación hasta este punto, y el Ser a secas, enfocándose a tal fin en la compleja e imprescindible noción merleau-pontiana de la chair. En este punto M. Larison examina en profundidad las más conocidas referencias al concepto en Le visible et l'invisible (1964), lado a lado con las más elípticas referencias de los seminarios contemporáneos a la 
redacción del primer texto, allí donde la noción de carne hace su aparición cuando "la noción de incorporación (surgida de un simbolismo primario) y el carácter reflexivo del sensible-sentiente (surgido de los análisis husserlianos del cuerpo propio) son presentados como los rasgos distintivos del cuerpo humano" (p. 169). Desarrollando una apuesta hermenéutica compleja y original que logra integrar los múltiples acercamientos merleau-pontianos al concepto, los análisis de Larison muestran en primer término que la carne es una forma que adquiere el cuerpo humano, a saber, la de la reflexividad de lo visible, sólo cumplida mediante el pasaje por lo otro de sí mismo e instituyendo así una "forma subjetiva" inseparable del campo en el que opera. Ahora bien, como forma que encarna un cuerpo la carne no se reduce a él, y es desde estos términos que se ilumina el sentido propio del difícil concepto de una "carne del mundo" como "mundo en el sentido de una estructura humana": los cuerpos estesiológicos "son cuerpos humanos en el interior del horizonte del mundo humano, carne del mundo, articulación de visible y reflexividad. [...] La relación del cuerpo al mundo se supera así en una relación del mundo a cada una de sus partes. Esta superación dialéctica provoca una inversión de perspectivas entre lo finito y lo infinito, y es ésta la que representa - en nuestra visión- la apuesta de la última filosofía merleau-pontiana: la apuesta de la afirmación simultánea y del pasaje en doble sentido de una fenomenología de la forma a una ontología de lo percibido" (p. 179).

El cuarto y último capítulo - "Ontologie, dialectique et phénoménologie de la forme"- culmina en una consideración conjunta y en integridad del último proyecto filosófico merleau-pontiano, comenzando con el examen del seminario que dictara el filósofo en los años 1955-56 acerca de la dialéctica, considerado en sí mismo por la autora como un programa de investigación que sería desarrollado en los años subsiguientes hasta llevar a los últimos desarrollos ontológicos. Desde esta perspectiva, la última ontología evidencia haber sido concebida desde el inicio como "una ontología de la mediación centrada en la idea del Ser como forma percibida" (p. 184), idea que se muestra así indisociable de la búsqueda de una "buena dialéctica" que ya atravesó hasta este punto la investigación de la noción de naturaleza y de la corporalidad viviente. Las relaciones entre la ontología de lo percibido y la dialéctica -entendida aquí por MerleauPonty a la vez como un "pensamiento de contradictorios", "subjetivo" y "circular" - son elucidadas mediante un minucioso análisis de este seminario, comen- 
zando por desglosar tres contradictorios dialécticos. En primer lugar se aborda la dialéctica del ser y la cosa entendida como forma, figura sobre fondo, y mediación de finitud de aspectos e infinitud de despliegue de perspectivas. En segundo lugar se examina la dialéctica del ser y el mundo - signado por la tensión entre la individualidad extensiva y la generalidad comprehensiva de estilos de ser y de mundos-, y en tercer término, la dialéctica del ser y el universo tal como es atestiguada por la investigación científica contemporánea. A partir de estas dialécticas se delinea una original comprensión de la trascendencia de la cosa y del mundo como "ser a distancia", y una correlativa reformulación de la noción de subjetividad como a distancia de sí misma en tanto "no es una conciencia inmanente sino un campo de vida que permanece por debajo de la partición entre un orden de inmanencia y un orden de trascendencias" (p. 194), un momento inseparable del sistema que conforma con el mundo, la cosa y los otros. El carácter circular del pensamiento dialéctico es examinado por MerleauPonty atendiendo al retorno sin coincidencia de la reflexión sobre lo irreflejo, así como a las figuras temporales del ser total y parcial, la conservación y la novedad $y$, en suma, la "totalidad en movimiento que no subordina sus momentos a una identidad superior" (p. 197). Como advierte la autora, la relación dialéctica es entendida por Merleau-Ponty como relación perceptiva en un sentido "más próximo del lenguaje gestáltico de la figura y el fondo que de la concepción husserliana de la estructura de horizonte y de la síntesis subjetiva" (p. 198), abriéndose así el interrogante acerca de la posibilidad y la legitimidad de este singular deslizamiento teórico desde el registro ontológico de la dialéctica hacia el psicológico propio de la Gestalttheorie. Para dilucidar este punto, M. Larison precisa las oscilaciones que signaron los orígenes mismos de la escuela gestáltica y su recepción francesa, así como los diversos modos en los que MerleauPonty retomó aquellos desarrollos. Si en su Phénoménologie de la perception el filósofo vertió los análisis gestálticos en términos de esquema corporal y los encuadró en un marco intencional de carácter subjetivo, desde principios de los años '50 apostó en cambio a un retorno a la figura de la Gestalt en los términos mismos de la Gestaltpsychologie, sólo que depurados de su lastre realista e integrados originalmente con la noción saussureana de "estructura". En este punto, la atención concedida en los análisis de la autora al curso aún inédito acerca de "Le problème de la parole" (1953-54) aporta elementos de singular interés para comprender esta difícil amalgama. La noción de Gestalt podrá con- 
sagrarse como una figura central de la última ontología merleau-pontiana sólo por medio de esta reformulación en términos de "una estructura fenomenal auto-regulada, de un sistema diacrítico de oposición que organiza tanto sus momentos subjetivos como fenomenales" (p. 221). La estructura del ser podrá ser designada así como "«il y a» originario, [...] fenómeno visible sostenido por una estructura invisible que remite por sí misma a una mirada perceptiva como uno de sus momentos necesarios" (p. 222). Desde estos términos pudo elaborarse una ontología de lo sensible como la que esboza Le visible et l'invisible, que partiendo de la evidencia del "algo" y de la fe perceptiva, avanza en la crítica de la intuición husserliana de la esencia y la intuición bergsoniana del ser. Así se abre la posibilidad de pensar una esencia inseparable del hecho, de lo sensible y de la expresión, y un ser de la cosa con el que no es posible coincidir, porque está siempre en génesis y nunca acabado: "la ontología de lo sensible no puede ser más que una ontología de la mediación, una ontología indirecta" (p. 241).

La segunda parte de este último capítulo se interroga acerca de la inscripción de este último proyecto ontológico en la corriente fenomenológica, a partir de la pregunta metodológica más fundamental acerca del tipo de reflexión adecuado para dar cuenta del ser en los términos dialécticos ya precisados. Para ello se indaga primeramente en las particularidades de la efectiva recepción merleau-pontiana de la fenomenología de Husserl, sus distancias respecto de la interpretación de A. Gurwitsch - de quien recoge la evidencia de la relación esencial entre fenomenología y Gestalttheorie- y la más significativa impronta de la interpretación de E. Fink del problema central de la fenomenología como acceso al sentido del ser respecto del cual se subordinan los de la conciencia y el objeto. Si Merleau-Ponty prolonga aun más allá de Fink la tesis de la irreductibilidad del ente al objeto, cabe preguntarse, tal como lo hace la autora, "si es posible renunciar a la versión objetivista de la fenomenología [...] apelando a la tradición de pensamiento surgida de Husserl" (p. 268). Evitando el camino corto de apelar a las relecturas merleau-pontianas de tal o cual noción husserliana -en los estudios más usuales, nociones características de las etapas genética o generativa de la producción de Husserl-, en este punto Larison opta por emprender un análisis original y minucioso del problema del ser tal como está ya implicado desde la definición "intencional" de los fenómenos psíquicos de Brentano y la reformulación husserliana de esta tesis en sus Investigaciones Lógi- 
cas, donde la concepción de una intuición categorial lleva a término la identificación del ser y el objeto. Desde este marco, la última filosofía de MerleauPonty se revela como el desarrollo de un problema inherente al núcleo mismo de la fenomenología desde sus más incipientes orígenes: el de la invisibilidad del ser. Frente a la opción husserliana de ampliar las nociones de objeto y de intuición, Merleau-Ponty extiende la concepción de lo sensible de modo tal que "lo invisible - la estructura - [...] no corresponde a la objetividad ideal, sino que reside en el fenómeno sensible de tal manera que no podría hacerse abstracción de la estructura sin destruir enteramente el fenómeno" (p. 281). Dar cuenta de la dimensión estructurante del fenómeno sensible en estos términos significa, para la última "fenomenología de las formas" merleau-pontiana, pensar el fenómeno intencional como Gestalt -estructura figura-fondo, "estructura de todo ser como «il y a» originario". (p. 291) - comprendiendo correlativamente el carácter subjetivo del aparecer en términos de un "campo perceptivo" relativo a una carne.

Al término de esta precisa elucidación del itinerario del último pensamiento de Merleau-Ponty, una ontología de las formas sensibles en la que el sentido del ser incluye la negatividad se manifiesta como indisociable de las preocupaciones más propias de la filosofía fenomenológica y, simultáneamente, como surgida de la interrogación merleau-pontiana acerca de la dialéctica de mediados de la década del '50. Sumándose al mérito de los exactos y originales análisis ya reseñados, el examen de este último punto constituye por sí mismo el hallazgo de un "eslabón perdido" en la interpretación de la última filosofía merleau-pontiana. Esto permite integrar sus multívocas figuras en un escenario teórico coherente, y -retomando aquí las acertadas palabras del Prefacio de R. Barbaras- dota al presente trabajo de un valor inestimable "como referencia para todo aquel que se interese en la obra de Merleau-Ponty, y más allá de ella, en la filosofía francesa del último siglo" (p. 13). 